Case Report

\title{
Analysis of a High-Voltage Room Quasi-Smoke Gas Explosion
}

\author{
Marit Sigfrid Bakka ${ }^{1}$, Erling Kristian Handal ${ }^{1}$ and Torgrim Log $2,3, * \mathbb{C}$ \\ 1 Corporate Accident Investigations, Equinor, 5253 Sandsli, Norway; marbak@equinor.com (M.S.B.); \\ erlhan@equinor.com (E.K.H.) \\ 2 Department of Safety, Chemistry and Biomedical Laboratory Science, Fire Disaster Research Group, \\ Western Norway University of Applied Sciences, 5528 Haugesund, Norway \\ 3 Kårstø Gas Processing Plant, Equinor, 5565 Kårstø, Norway \\ * Correspondence: torgrim.log@hvl.no; Tel.: +47-900-500-01
}

Received: 23 December 2019; Accepted: 27 January 2020; Published: 29 January 2020

\begin{abstract}
During an air separation unit shut-down in a methanol production plant, a stop signal was sent to the control cabinet of a synchronous motor for a booster compressor. The control cabinet stopped magnetizing the rotor, while the system logic ensured that the power circuit breakers for the start reactor coils were opened, in order to be ready for the next start-up. Unintentionally, the circuit breaker was still connected (i.e., power was let through the reactors for a prolonged time period), which led to extensive overheating. Subsequently, the central control room received an unaddressed sub-station smoke alarm, and plant operators were sent out to locate the possible source of smoke. The accessible rooms were searched, and traces of smoke were confirmed. The Emergency Response Organization (ERO) was mustered and, through inspection, the Emergency Response Team (ERT) realized that the smoke originated from a ground floor high-voltage room. Fire hoses were arranged for fire extinguishing, and the ERT withdrew to wait for the room to be electrically isolated. About one minute after briefly opening the only set of doors to the high-voltage room, flames were observed, and a quasi-smoke gas explosion violently forced both door blades open and released a substantial fire ball. Personnel had been in the risk zone shortly before the explosion, but luckily no personnel were hit by the slamming door blades or the emerging flames. The incident revealed several learning points related to improper maintenance, ambiguous smoke alarm, lack of flame detectors in the high-voltage room, insufficient risk understanding and training regarding electrically related fire incidents, and the absence of an automatic fire suppression system. In plants processing hydrocarbons, the safety focus regarding hydrocarbon fire and explosion risk is paramount. However, risks related to electrical accidents and compartment fire dynamics (e.g., backdraft and smoke gas explosion) should also be given proper attention.
\end{abstract}

Keywords: quasi-smoke gas explosion; learning points; high-voltage room; electrical sub-station; safety measures

\section{Introduction}

The processing of hydrocarbons is associated with risks of fire and explosions. Much learning has been gained from studies of previous accidents (e.g., the Piper Alpha disaster in 1988 [1-3] and the Texas City Refinery disaster in 2005 [4-6]). Preventing new accidents involves relentless work on improving all aspects that can influence the risks, and thus requires much focus in the oil and gas industry. Major accident prevention certainly needs attention. There are also other risks involved in production sites such as falling objects and electrical incidents, which have also received due attention. Sometimes, however, incidents associated with other fields of safety may result in highly unforeseen 
accidents that may not be sufficiently covered in the normal fire and safety training programs for typical oil and gas industry facilities.

Fires in buildings traditionally follow classical compartment fire growth. They typically start with an incipient phase, leading to a growth phase that suddenly transitions through flashover into a fully developed phase and ends with a decay phase [7]. These phase definitions are used by firefighters, engineers, researchers, and scientists when describing and analyzing compartment fires. Most of the research on compartment fires has dealt with this classical fire development, which by far represents the most likely fire scenarios in buildings. Some other special fire scenarios are, however, also well known to firefighters (i.e., backdrafts and smoke gas explosions). These scenarios are much less frequent, but may expose the firefighters to unexpected extreme conditions.

In the literature, the phenomena of backdraft and smoke gas explosion may be intermixed, but they are indeed quite different mechanisms [8]. Backdraft may happen when a developed fire becomes partially choked, but still burns (smolders) and releases many combustible pyrolysis products [9]. Given access to ambient air, typically through the introduction of a ventilation opening (e.g., a door opened by the firefighters), the combustible oxygen-depleted atmosphere may ignite in contact with remaining small flames or smoldering particles. This results in a flame ball being ejected through the ventilation opening (e.g., a door opened by the firefighters). A smoke gas explosion usually happens when gases from an under-ventilated fire flow through small openings into a confined space, mix with air, and accumulate to form a combustible gas mixture [9]. A flame from the original fire or a hot ember entering the adjacent smoke-filled room may then ignite this combustible gas mixture. Since this happens without altering the ventilation conditions (i.e., in a closed compartment), the resulting combustion process may result in substantial explosion pressures [8].

One may also consider a situation where the overheating of combustibles in a compartment results in significant smoke production (i.e., with no previous fire in a closed compartment). As the released pyrolysis products accumulate and at the same time become well mixed with air, the total concentration of combustibles in the smoke layer may reach concentrations above the lower flammable level. If the closed compartment smoke gas is ignited, the resulting combustion process may result in substantial explosion pressures. In the present study, an incident like this would be named a "quasi-smoke gas explosion", since a fire was not the source of the smoke gas production.

Research on electrical sources of fires in civil and industrial buildings is scarce, and standards are often based on limited research or the research presented in early Japanese-language scientific articles [10]. More research has been done regarding overhead power line conductors clashing as the ignition source of wildland fires [11-13]. Other accident mechanisms have gained more attention, for example, arcs as a cause of fire [14] or lightning strikes as a risk to personnel and electrical equipment [15]. It has, however, not been possible to find research in relation to overheating, resulting in subsequent quasi-smoke gas explosions, even though electrical equipment certainly has the potential to produce pyrolysis products that may subsequently ignite, unless the power is quickly disconnected.

The purpose of the present study was to analyze an incident involving the excessive heating of high-voltage room reactors for an electrical booster compressor motor, resulting in a surprising and violent explosion of the pyrolysis products. Since the source of the pyrolysis products was electrically overheated equipment and cabling, and not a smoldering fire, the incident differs from traditionally defined smoke gas explosions. The motivation for the analysis is to share possible learning points, to prevent similar incidents from recurring in the oil and gas industry and other industries dealing with high-voltage rooms for operating power-intensive equipment. The incident is described in Section 2. The analysis of the factors leading to the explosion is described in Section 3. In Section 4, the findings and the way forward for preventing such incidents are discussed.

\section{The High-Voltage Room Incident}

On 19 December 2018, some malfunctions occurred in the methanol plant air gas separation unit, after a compander had tripped due to vibrations. This resulted in a plant shut-down, and the 
separation unit had to be attended to, in order to restart production. In order to efficiently utilize the downtime, it was decided to carry out planned maintenance work while repairing the separation unit. Simultaneously, a liquefied natural gas (LNG) production line was prepared for start-up. Additional personnel were called for, and personnel were redeployed to carry out the necessary tasks.

A stop signal was sent to the control cabinet of a synchronous booster compressor motor. The control cabinet stopped magnetizing the rotor, while the system logic ensured that the circuit breakers for the start reactors/coils were opened, ready for a later start-up. Unintentionally, the power circuit breaker for the booster compressor motor was still connected. This led to power through the reactors for a prolonged period of time. Based on the available information on the control room screens, the stop signal was, however, interpreted as meaning that the booster compressor had stopped, and that the air gas separation unit was fully tripped. The focus then shifted toward the LNG production line start-up. It was registered that an oil pump did not start as it should have when the booster compressor was stopped, but there was no feedback informing that the reactor spools were still engaged. The pump was therefore activated manually. The electro control supervisory system (ECSS) received many alarms about overcurrent, but these alarms were only sent to the process control and data acquisition (PCDA) system event log.

The combination of the above events resulted in a period of overcurrent in the 11-kV high-voltage surge protector (i.e., a system that can handle a large current for the limited time period associated with the start-up of the booster compressor). However, continuous power through the reactor spools will gradually lead to severe overheating. Approximately $16 \mathrm{~min}$ after the booster compressor had been given the stop signal at 10:15:54, an alarm from the air separation unit sub-station fire central indicated a "Sub-Station Fire Pre-Alarm" on the central control room fire and gas (F\&G) panel at 10:32:39. At 10:32:44, it was followed by a "Sub-Station Fire Alarm".

The plant operators decided to search the rooms that they had access to. After the operators had reached the sub-station first floor and inspected a local equipment room (LER), they could smell smoke and thereby confirmed a potential fire scenario. They also noticed that the smoke came up through the computer room floor and that the smoke ingress rate was increasing. It was then decided to look for smoke production on the ground floor. At about the same time, the control room received a new alarm from another smoke detector in the LER. The emergency response team (ERT) was called to take over the search for the smoke source. Next, the operators located smoke spreading from the ground floor high-voltage room where the booster compressor start reactors were located. This room only has an external door, which was opened for $2 \mathrm{~s}$ at 10:46:52. The source of smoke production was confirmed to be within the room. After closing the door, the operators withdrew while waiting for the arrival of the ERT.

Upon arrival at the scene of the smoke source, the ERT confirmed the smoke production by briefly opening the door at 10:48:28, and then prepared for action using $\mathrm{CO}_{2}$ hand-held fire extinguishers. The ERT leader repeatedly ordered the control room to shut down the power supply to ensure safe access. The on-call electrician, who normally has one hour to mobilize, happened to be at the facility for another job and hastened to the central control room to disconnect the high-voltage room. During this period, more smoke detectors signaled smoke in the sub-station. At the incident site, preparations were also made for fire suppression with water in case the hand-held extinguishers were not sufficient. Fire hoses were therefore arranged next to the high-voltage room door. Personnel in the ERT retreated from the high-voltage room door, while awaiting confirmation of electrical isolation. Shortly afterward, flames were observed from the high-voltage room, immediately followed by an explosion at 10:50:06, as the smoke gases in the high-voltage room ignited, violently forcing the door blades open, as seen in Figure 1.

At this point in time, no one from the ERT was in close proximity to the high-voltage room door. Nobody was injured by the fire or the explosion, but ambulance, police, and the local fire department arrived at the plant, in accordance with normal procedures. The yellow personnel indicators in Figure 1 show that the personnel had been very close one minute earlier, and that when opening the door, 
one operator without personal protective equipment (PPE) had been severely at risk. Although nobody was injured, the incident was recognized as a close call. It was therefore decided that the incident should be analyzed and presented to the high-voltage and safety research community for common learning in sectors using high-voltage equipment.

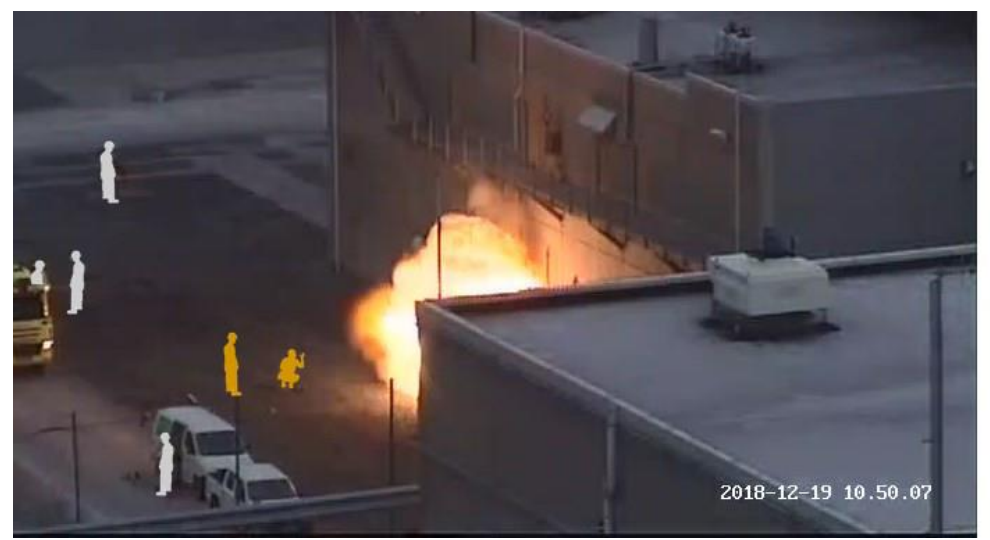

Figure 1. Closed-circuit television (CCTV) photo including location of personnel during the explosion (in grey) and approximately one minute earlier (in yellow) [16].

\section{Analysis of the Conditions Leading to the Incident and of Personnel Risk Exposure}

\subsection{Overheating of the Start Reactor Spools}

The booster compressor consists of several parts, of which the motor and the compressor are the most conspicuous items. The motor consists of a stator and a rotor, weighing 8 ton and 7 tons, respectively. The stator is supplied with current from two start reactors in order to reduce the voltage over the stator, for easier start-up. The start reactors function as voltage dividers. The synchronous motor needs support to get started, and the rotor needs a magnetizing circuit to create a magnetic field.

At start-up, start reactors 1 and 2 are in series with the motor, limiting the voltage drop over the stator and thereby limiting the current. After achieving a certain number of revolutions per minute $(R P M)$, reactor 2 is engaged by short circuiting reactor 1 and preventing current through it. When synchronous RPM is nearly achieved, the other switch short circuits reactor 2 . If this is not achieved within a specified time period, the start sequence is aborted. When the motor is later halted, all the effect switches are opened, ready for the next start-up.

When the booster compressor was still running and the reactor spools were still engaged, the current flowing through them should have been $1770 \mathrm{~A}$ or $1930 \mathrm{~A}$, respectively, for the start reactors of $0.3 \Omega$ and $1.0 \Omega$. This current does not harm the reactors, while gradually heating the spools for a short period of time. Prolonged periods of heating (i.e., minutes) would, however, lead to severe overheating. The continuous heating was most likely caused by a failure in a relay, electrically insulated with polyamide, as presented in Figure 2. The investigations revealed that this relay had much friction, preventing it from operating properly. White crystals, chemically identified as adipic acid, were collected from the relay, as seen in Figure 2. Adipic acid may be a decomposition product from polyamide and may have caused the friction, leading to a stuck relay and prolonged reactor engagement.

There was no separate thermal protection system monitoring the reactor temperatures. They were only monitored by the logic controlling the magnetization. As the reactor spools were continuously engaged, and heating up, they started to decompose/pyrolyze the electrical insulation materials, leading to smoke production and a potentially ignitable smoke layer trapped beneath the high-voltage room ceiling.

There was a smoke detector in the high-voltage room, where a total of four start reactors were located, two for the booster compressor motor and two for the main air compressor motor. This smoke 
detector gave an alarm signal to the local fire central, which only forwarded the message "Sub-Station Fire Pre-Alarm" to the main control room. Since this message was general, the high-voltage room was not inspected early in the incident. The reactor spools and wiring continued to heat up and produced significant amounts of decomposition products and pyrolysis gases. Intact spools, and spools with carbonized electrical insulation (in the background) are shown in Figure 3.

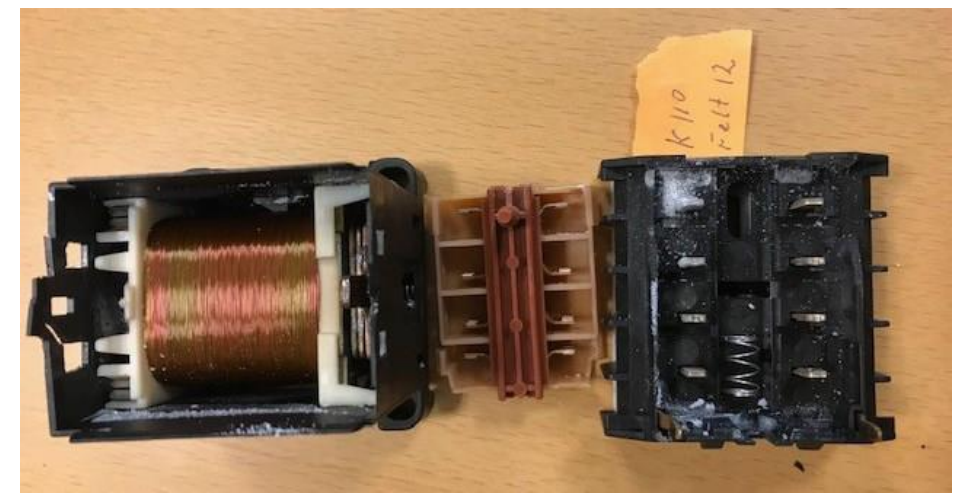

Figure 2. Relay with traces of white adipic acid crystals [16].

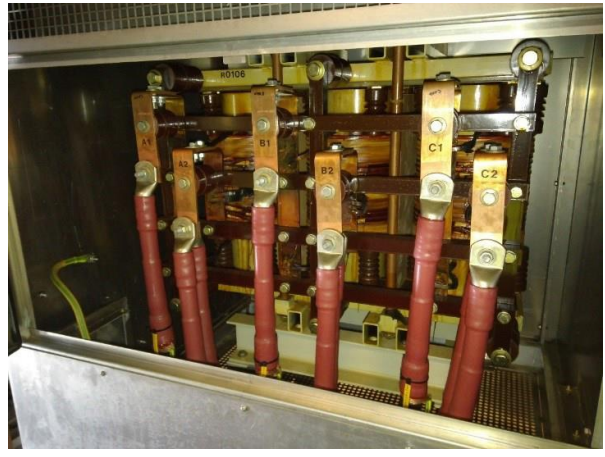

(a)

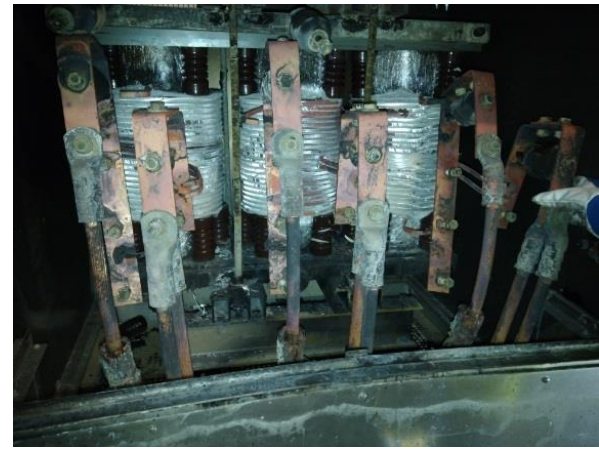

(b)

Figure 3. Intact reactor spools (a) and reactor spools with insignificant remains of carbonized insulation material (b) [16].

\subsection{Estimate of Accumulated Pyrolysis Products}

A cable representative of the wiring that became overheated and resulted in a massive release of decomposition (pyrolysis) products is shown in Figure 4. It consisted of a copper core, insulated by a crosslinked polyethylene (XLPE) layer and a polyethylene (PE) layer, and was protected by copper and PE. The dimensions are given in Table 1. The estimated volume of plastic products (i.e., XLPE and PE) per meter cable is also presented in Table 1.

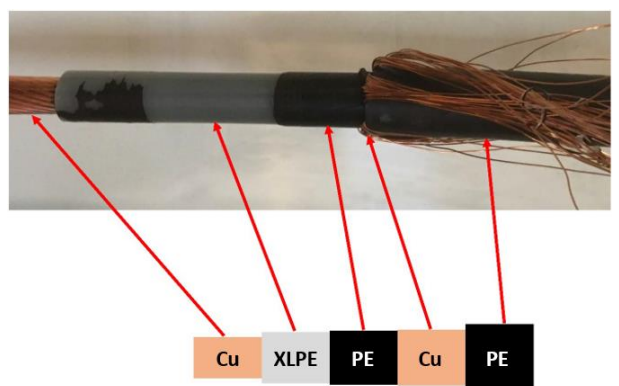

Figure 4. A representative copper $(\mathrm{Cu})$ cable opened to show the layers of cross-linked polyethylene (XLPE) and polyethylene (PE) insulation, as presented in Table 1 [16]. 
When heating XLPE and PE to about $400{ }^{\circ} \mathrm{C}$, ethylene, hydrogen, and soot products as well as numerous other products start to form [17]. In this particular case, about a 10-meter length of cabling was pyrolyzed, with only a minimum of residue on the cabling. According to Table 1, $10 \mathrm{~m}$ of cabling corresponds to about $8.3 \mathrm{~L}$ of PE and XLPE being pyrolyzed. It was evident that the aluminum ceiling in one of the cabinets had melted, indicating temperatures above the melting point of aluminum (i.e., above $660^{\circ} \mathrm{C}$ ).

Table 1. Materials pyrolyzed from the TXSP 6/10 (12) kV in the reactor cabinet.

\begin{tabular}{ccccccc}
\hline Dimension & Copper & XLPE & PE & Copper & PE & Sum Pyrolyzed \\
\hline Periphery $(\mathrm{mm})$ & 78 & 99 & 106 & 111 & 133 & - \\
Diameter $(\mathrm{mm})$ & 24.8 & 31.5 & 33.7 & 35.4 & 42.3 & - \\
Cross section $\left(\mathrm{mm}^{2}\right)$ & 484 & 780 & 894 & 985 & 1408 & - \\
Thickness $(\mathrm{mm})$ & 12.4 & 3.3 & 1.1 & 0.8 & 3.5 & - \\
Volume $(\mathrm{L} / \mathrm{m})$ & 0.484 & 0.296 & 0.144 & 0.091 & 0.423 & - \\
Pyrolyzed $(\mathrm{L} / \mathrm{m})$ & - & 0.296 & 0.144 & - & 0.423 & 0.83 \\
\hline
\end{tabular}

Since the pyrolysis products were hotter than the ambient air, the resulting buoyant plume entrained air, while rising to the ceiling [7]. As above-mentioned, at 10:46:52, the door to the high-voltage room was opened. This resulted partly in the ventilation of pyrolysis products, as seen in Figure 5 . It can be clearly seen that the smoke was lighter than the ambient air and rose buoyantly when released through the door opening. It should be noted that the operator at ground level, not visible in Figure 5, did not see any open flames when looking into the room, either at the electrical equipment releasing pyrolysis products or in the smoke layer. The high-voltage room door was then closed, and the accumulation of combustible pyrolysis products under the ceiling continued and most likely accelerated with increasing spool and wire temperatures [17]. At 10:48:50, an operator, fully dressed in firefighter PPE, slightly opened the door to evaluate the situation and then quickly closed it. Two minutes and 25 seconds later, the smoke gas ignited and resulted in an explosion, violently forcing the door of the high-voltage room open. A two-second CCTV photo sequence of the smoke gas explosion is shown in Figure 6.

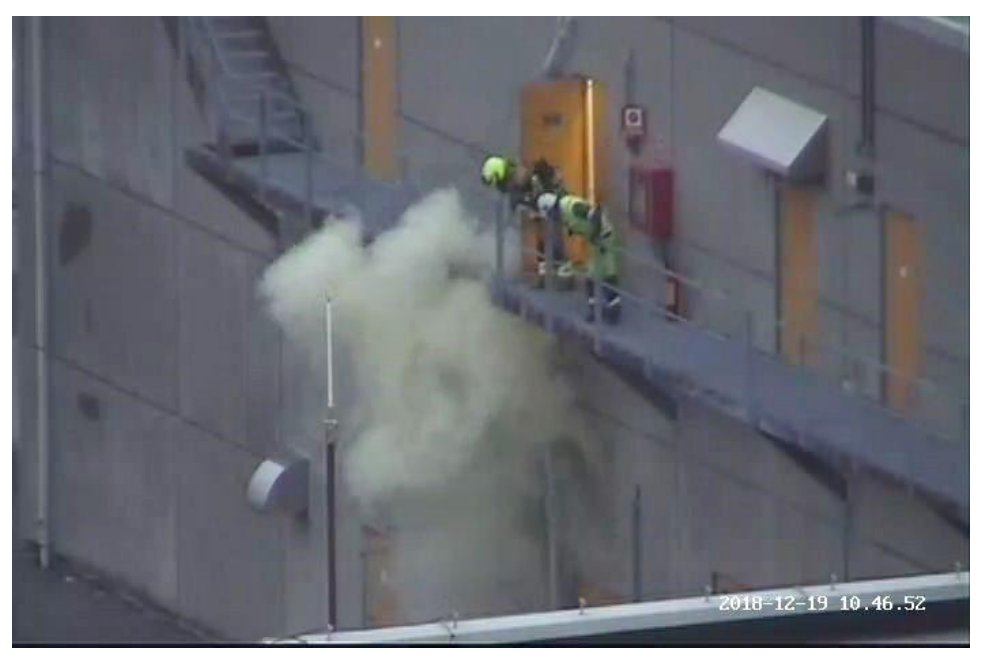

Figure 5. Pyrolysis products ventilated when briefly opening the door to the high-voltage room at 10:46:52 [16]. 

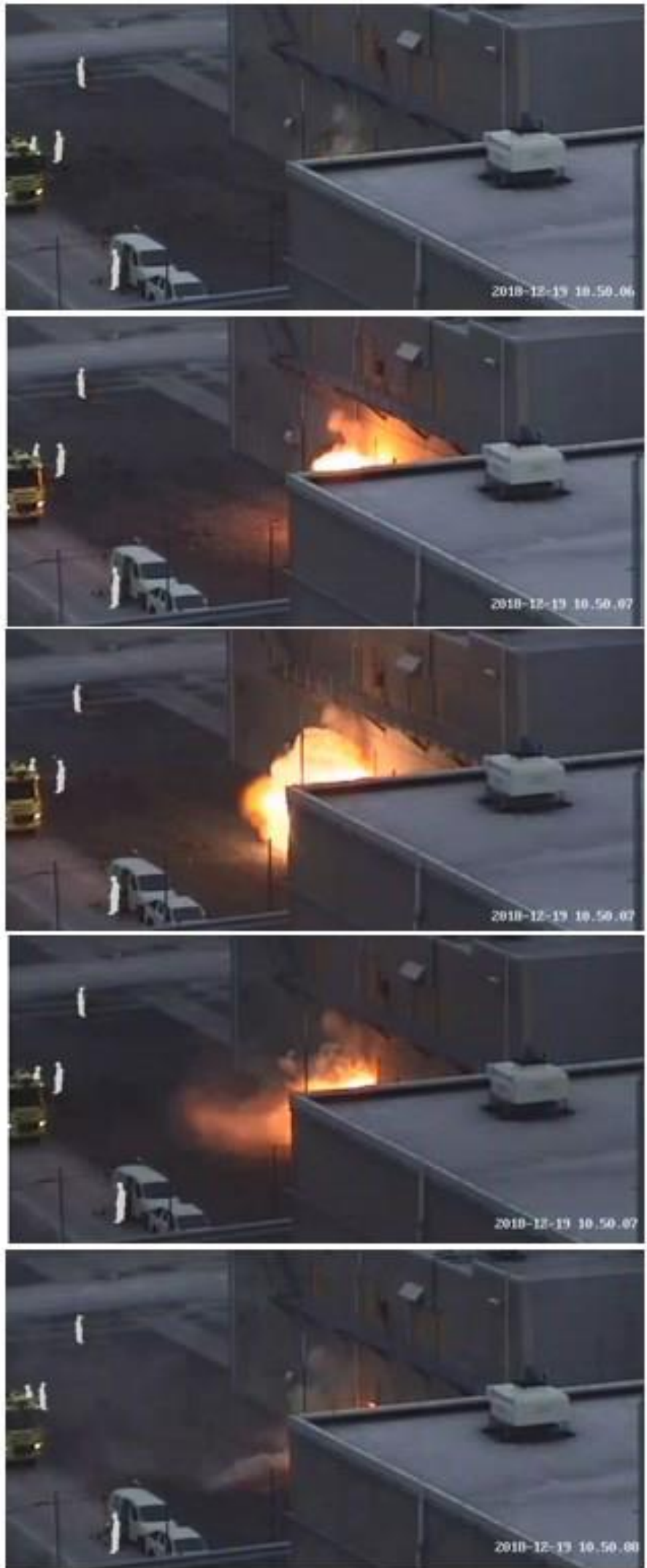

Figure 6. A two-second sequence of photos showing the explosion at 10:50:06-10:50:08. The location of personnel in close vicinity to the ignition is shown as white markers [16]. 
The sub-station is a solid concrete building, designed to survive certain external explosion loads. It was therefore quite robust regarding possible internal explosion forces. The weakest point was the closed high-voltage room entrance door, which was slammed open. It thereby acted as an explosion pressure vent. A photo of this double door, after the smoke gas explosion, is shown in Figure 7.

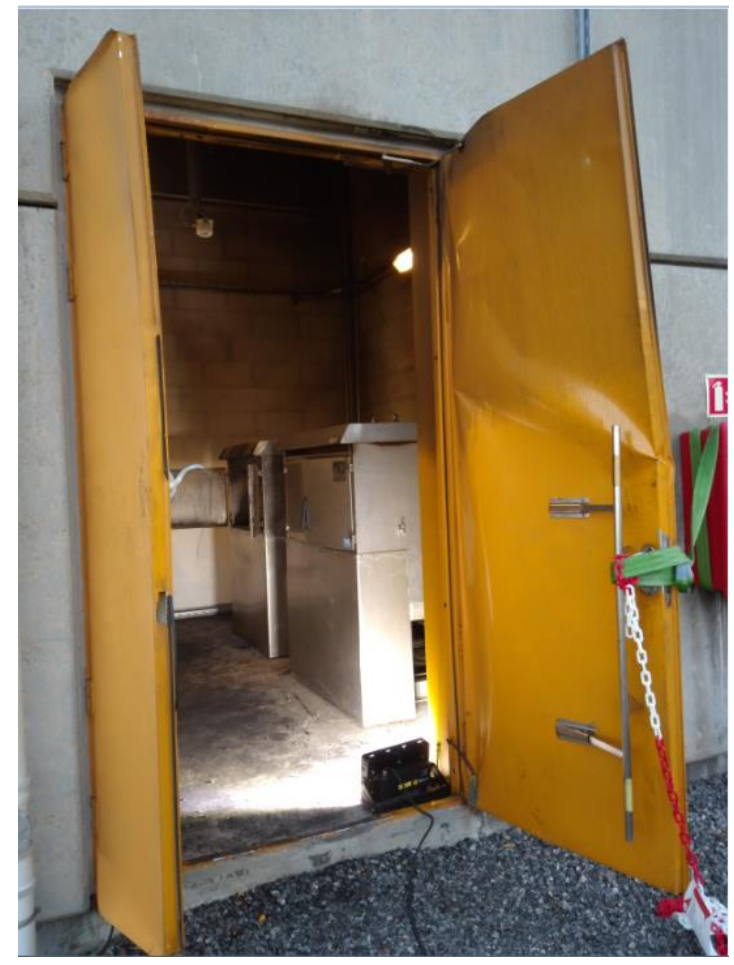

Figure 7. The high-voltage room door after the explosion [16].

With a density of about $0.9 \mathrm{~kg} / \mathrm{L}$, the $8.3 \mathrm{~L}$ of pyrolyzed material corresponded to a mass loss of about $7.5 \mathrm{~kg}$. The insulation materials at the reactor spools, probably resin or varnish, also resulted in pyrolysis products when heated. After the explosion, there were some soot settlements on the walls and ceiling, but only negligible amounts had settled on the floor. Taking $7 \mathrm{~kg}$ as the mass of the accumulated pyrolysis products in the smoke layer trapped beneath the ceiling thus seemed to be a fair assumption.

\subsection{Were There Sufficient Pyrolysis Products for a Quasi-Smoke Gas Explosion?}

According to the literature, backdrafts and smoke gas explosions share a similar initial condition, originating from poorly ventilated fires releasing excessive amounts of pyrolysis products. The pyrolysis products released in the studied case did not result from a fire (i.e., the scenario is therefore not strictly a traditional backdraft or a smoke gas explosion). The term quasi may be introduced to indicate that the incident was not initiated by a fire. Backdrafts, with oxygen-depleted smoke, must experience a change in ventilation conditions (i.e., a supply of oxygen) for smoke gas combustion to take place. Smoke gas explosions, which already have sufficient oxygen, only need an ignition source for sudden combustion. To evaluate whether the case studied was a scenario similar to a backdraft, (i.e., a quasi-backdraft), or similar to a smoke gas explosion (i.e., a quasi-smoke gas explosion), the availability of oxygen in the smoke layer must be analyzed. In a choked quasi-backdraft scenario, the improved ventilation could have been due to opening the door twice. In a quasi-smoke gas explosion, the ignition source could have been the hot reactor spools and cables, which resulted in temperatures above the melting point of aluminum. It cannot be ruled out, however, that the experienced short circuit may have resulted in an arc, and that this arc ignited the combustible smoke gas. 
In order to ignite the smoke gas, the concentration of pyrolysis products needs to be between the respective lower flammability (LFL) and upper flammability (UFL) limits. For instance, for a mixture of alkanes, the LFL may be calculated based on an adiabatic limiting flame temperature of about $1500 \mathrm{~K}$ to $1600 \mathrm{~K}$ [7]. The LFL for pyrolysis gases may be far more difficult to estimate. However, since the XLPE and PE consist of ethylene, with flammability limits between $2.6 \%$ and $36 \%$, corresponding to $35 \mathrm{~g} / \mathrm{m}^{3}$ to $700 \mathrm{~g} / \mathrm{m}^{3}$, this gives an indication of the concentrations required to create an ignitable smoke gas. Hydrogen has a LFL of $3.6 \mathrm{~g} / \mathrm{m}^{3}$, while alkanes generally have a LFL in the range, $40-50 \mathrm{~g} / \mathrm{m}^{3}$. It may be reasonable to assume that the pyrolysis products had a LFL similar to that of general hydrocarbons (i.e., $45 \mathrm{~g} / \mathrm{m}^{3}$ ), and a UFL in the range of $200-300 \mathrm{~g} / \mathrm{m}^{3}$ [7].

Since there were particles and aerosols in the smoke layer, the smoke gas might not have ignited as easily as pure hydrocarbons. Knowing, however, that there were hot surfaces in the room (i.e., at temperatures above the melting point of aluminum), and maybe a short-circuit arc, there was certainly a high probability of a smoke gas ignition.

The interior dimensions and the layout of the high-voltage (reactor) room are shown in Figure 8. The volume of the room was about $123 \mathrm{~m}^{3}$. The interior surfaces were essentially exposed concrete, with very few combustibles. It basically contained the four rector spools including their associated cabling. The reactor spool units tagged 34EY4002 and 34EY4003 were connected to other equipment at the plant and did not suffer any damage in the incident. The reactor tagged 34EY4004 was severely damaged due to overheating, as seen in Figure 3b, while the reactor spool unit tagged 34EY4005 was less damaged. Assuming that about $7 \mathrm{~kg}$ of electrical insulation materials were pyrolyzed, this would give a concentration of about $57 \mathrm{~g} / \mathrm{m}^{3}$ if the whole room volume was involved, or $85 \mathrm{~g} / \mathrm{m}^{3}$, if only the upper two thirds of the room were filled with smoke. Although some particulate materials and aerosols may have settled on available surfaces, it can be concluded that at least the upper part of the room was filled with ignitable smoke gas, with concentrations between the LFL and the UFL.

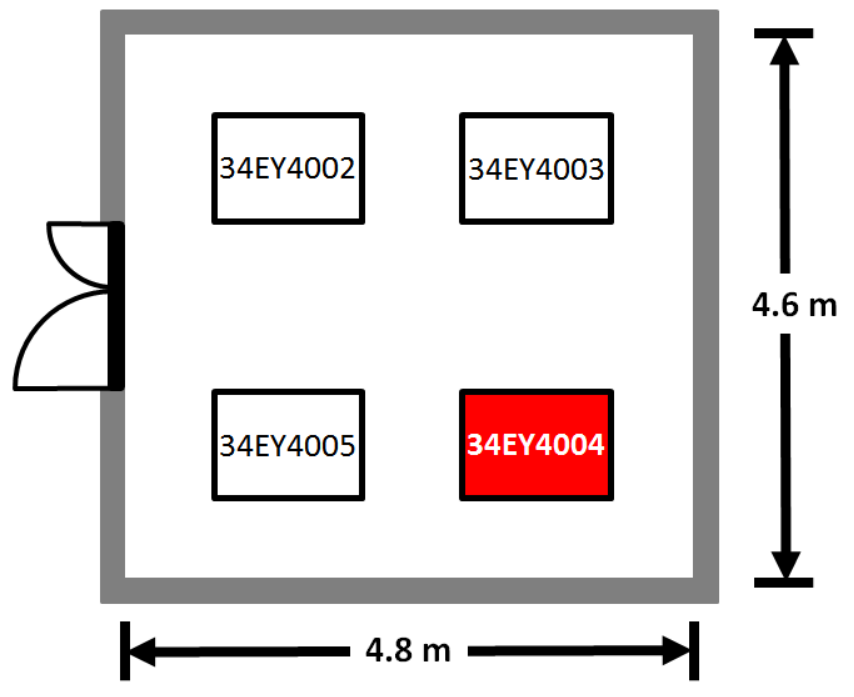

Figure 8. The high-voltage (reactor) room layout and dimensions including tag numbers and internal dimensions. The equipment that overheated is marked in red.

A backdraft would require an oxygen-depleted atmosphere. However, in this case, the pyrolyzed materials gave a concentration of volatiles well below an estimated UFL. This indicates that there was sufficient oxygen available for the combustion process. A backdraft due to the opening of the door can therefore be ruled out as the explosion mechanism.

The heated reactor, 34EY4004, possesses several of the characteristics of the smoldering fire, causing smoke gas explosions [8]:

1. located away from the ventilation opening, 
2. occurring within a smaller cabinet within the compartment, and

3. located higher than the floor, preventing oxygen-rich air from reaching the "burning" zone.

Since there was sufficient oxygen for complete combustion, marginally increasing the already sufficiently high oxygen concentration by briefly opening the door twice likely had no influence on the forthcoming explosion. A local sudden puff of fresh air can, however, be sufficient to ignite pyrolysis products from smoldering sources. A puff could maybe also ignite overheated cabling. In this case, the last time the door had been slightly opened was, however, $1 \mathrm{~min}$ and $38 \mathrm{~s}$ before the explosion. During this time period, any puffs would most likely have weakened due to levels well below the buoyant plume speeds associated with the electrically overheated equipment. It can therefore be concluded that opening the door most probably did not influence the development of this particular explosion. The combustible smoke was most likely ignited by the electrically heated surfaces or the major short circuit that took place virtually at the same moment as the explosion. The explosion experienced was therefore closer to a smoke gas explosion than to a backdraft. Naming this incident a "quasi-smoke gas explosion" may describe it quite well.

The flame colors seen in Figures 1 and 6 indicate approximate flame temperatures near $900{ }^{\circ} \mathrm{C}$ [7]. Estimating the flame ball exiting the high-voltage room door at about $100-150 \mathrm{~m}^{3}$ indicates an immediate factor 2 expansion, relative to the initial reactor room of $123 \mathrm{~m}^{3}$. If the whole room was filled with an ignitable smoke gas, a resulting temperature of $900{ }^{\circ} \mathrm{C}$ would, according to the ideal gas law, have given an expansion of factor 4 (i.e., a flame volume of close to $500 \mathrm{~m}^{3}$ should then have been propelled out through the door opening). It may therefore be concluded that the ignitable smoke gas filled a fraction of the available $123 \mathrm{~m}^{3}$ (i.e., it did not fill the whole room). This conclusion is also supported by the soot marks on the door, as seen in Figure 7, indicating soot deposits on the upper part of the door and limited soot deposits on the lower part.

\subsection{Analysis of Potential Personnel Risk Exposure}

No personnel were injured in the explosion analyzed in the present study. It is, however, apparent that, when the dangers associated with smoke gas ignition were not realized, personnel were at risk when close to the high-voltage room door, either at the ground level or on the first-floor gangway just above the door. Given slightly changed circumstances, the explosion could have happened earlier (e.g., when personnel were close to the door). They could then have been hit by the slamming door blades and/or engulfed by the emerging flames.

The plant operators always wear fire protective clothing designed for short-term flame exposure. In mid-December in Norway, they also wear thermally insulated clothing under the protective working gear. This combination would limit the heat exposure significantly for short periods of (i.e., about 1-2 s) flame exposure. No skin burns would therefore have been expected on areas covered by the protective clothing, while some limited burns could have been expected on the hands, if wearing the thinnest protective gloves available.

If a person had been next to the door when the smoke gas ignited, the explosion pressure would likely have thrown them about, with resulting bruises and possibly broken limbs. Being hit by the slamming door could also have resulted in similar injuries. If engulfed by the emerging flames, severe injuries to naked skin would have been expected. Such large flames, as apparent from Figure 1, are close to being optically thick (i.e., with flame emissivity close to unity [7]). A person exposed to the emerging flame would most likely have had their hard hat blown off and possibly lost their glasses. Naked skin would most likely have developed severe burns due to the high radiation heat flux as well as the flame-to-skin convective heat transfer $[18,19]$. It should be noted that burns in the facial region are known to particularly represent a severe handicap for a person and may significantly reduce their, and their next of kin's, quality of life [20,21]. 


\subsection{Risk Perception and Training Programs}

In facilities processing highly combustible hydrocarbon products, the focus on combustible gas and liquid containment and the prevention of ignition sources rightly should have a very high focus. The same is the case for emergency operations for such incidents. Training sessions are therefore regularly arranged and attended by the plant operators and their line managers. This focus generally helps to understand the underlying risk related to hydrocarbon fires and explosions and how to minimize the impacts of developing incident scenarios. The combination of electrical overheating and a compartment where the smoke emitted by the overheated equipment and wiring became trapped beneath the ceiling represents a different scenario from that of typical oil and gas fires and explosions. The smoke gas explosion analyzed in the present paper was apparently not that well perceived. Phenomenologically, this situation was closer to what regular firefighters could be exposed to, and therefore trained to handle (e.g., flashover, smoke gas explosions, and backdraft scenarios [22,23]).

Without going into detail about the training programs, one may question whether the risk associated with electrical incidents, and maybe also general theory regarding enclosure fire dynamics, needs to be given more attention.

\subsection{Fire Alarm Systems for the Production Plant and the Sub-Stations}

There are usually two different fire alarm systems at gas processing and production plants in Norway. In the process areas, each detector is tagged, and each individual alarm is forwarded to the main control room. Structural (building) alarm systems are usually handled by a local alarm central, which forwards general alarm messages to the main control room. This is also usually the case for the facility sub-stations (i.e., similar to the situation in other large compartment buildings in Norway). Firefighters need to log into the local centrals, in order to read the addressed data from individual sensors.

For the air gas separation unit, the high-voltage rooms, the battery room, the low-voltage room, and the basement rooms were connected to the local fire central. In the sub-station, next to the local fire central, drawings showed the location of each individual detector. The plant operators had access to this local alarm central, but had no training in reading the data from it. Had there been a status display, the operators could quickly have looked at the drawings on the wall and located the activated smoke sensor.

\section{Discussion}

When investigating incidents, unknown issues and assumptions are needed to arrive at sound conclusions. In the quasi-smoke gas explosion analyzed in the present paper, there were fortunately several reliable information sources (e.g., alarm logs and PCDA recordings, trained plant operators, CCTV footage, and an emergency response log). Based on the friction in a relay, it could be concluded that this was the reason for the continuous engagement of the reactor spools. Based on the damage observed, it was quite certain that overheated reactor spools and electrical wiring represented the sources of the released combustible pyrolysis products. It is, however, not known whether ignition of the smoke gas was a result of the excessive overheating (hot surfaces in contact with combustible gases) or an electric arc. Both of these possible ignition sources seem quite likely.

The estimation of the PE and XLPE mass losses is quite rudimentary. The observation of a minimum of residue on the heated cabling is, however, in agreement with the thermogravimetric analysis (TGA) performed by Miandad et al. [17]. By heating test specimens at a rate of $10 \mathrm{~K} /$ minute, they found that PE had a two-stage decomposition process, where the initial degradation started at $270{ }^{\circ} \mathrm{C}$ and lasted until the temperature reached $385^{\circ} \mathrm{C}$. After that temperature, a sharp increase in degradation was observed, and $95 \%$ degradation was achieved with a further temperature increase to $485{ }^{\circ} \mathrm{C}$. They also observed a minimum of remains at temperatures above $510{ }^{\circ} \mathrm{C}$. Comparing the virtually char-free cabling observed in the present study with the TGA by Miandad et al. [17] 
indicates that the cabling was heated to temperatures in excess of $500{ }^{\circ} \mathrm{C}$. The mass loss experienced in the present study shows that there were sufficient pyrolysis products in the smoke layer trapped beneath the ceiling to make it combustible. The CCTV footage shows that the flames emerging after the explosion were smaller than expected, if the whole room volume had been involved in the smoke gas combustion process. This conclusion is also supported by significant soot marks only on the upper part of the door and the walls.

The studied quasi-smoke gas explosion incident fits well with the characteristics of smoke gas explosions listed by Bengtsson [24]. In particular, the violence of the explosion indicates premixed smoke gas and air combustion. While smoke gas explosions are quite rare, they represent a high risk to the firefighters handling the situation. Croft [25] analyzed 110 fires involving explosions, several of which resulted in firefighter fatalities and severe injuries. None of these smoke gas explosions were related to electrical overheating, but they do indicate the risk associated with the violent smoke gas explosions, regardless of the origin of the accumulated premixed pyrolysis products. Fortunately, nobody was hurt in the incident analyzed in the present study.

The non-addressed alarm to the central control room only indicated a general "Sub-station Fire Alarm". The plant operators were not trained to retrieve information from the sub-station fire central, which had to be accessed in the sub-station, nor were they instructed by the control room to retrieve this information. This resulted in the search of the accessible rooms, while only certified personnel had access to the high-voltage room.

Electrical components, especially those with mechanical movable parts, have a certain cycle of operation and therefore require monitoring, maintenance, and replacement at designated frequencies. In this case, a malfunctioned relay resulted in the severe overheating of the reactor spools, and thus the condition of relays should be included in the maintenance schedule.

The fact that the operators did not utilize the sub-station alarm central contributed to a significant delay during the fire investigation period. Addressed alarms from the sub-station would be the best approach to locating the fire early. Other detection systems such as infrared flame detectors might also have reduced this delay in this particular incident, and the inclusion of a voting system, for example, activation on two out of three detectors, could minimize the likelihood of false alarms. Overheating protection, which automatically disengages the equipment when it is too warm, is another approach for preventing severe overheating causing fire and explosion. Finally, an automatic suppression system offers protection to the safety of life and property by controlling or suppressing the fire upon activation.

Knowledge about the combination of smoke production and excessive heat would have been very helpful regarding anticipating the possible development into a serious incident. During the incident, an earlier conclusion about the possible scenario development would most likely have led to faster electrical isolation of the sub-station and likely prevented the explosion.

In Norway, there has generally been reluctance to consider water mist systems for fire control in high-voltage rooms. However, recent research has shown that this may be feasible [26]. Activating a water mist system eliminates the risk to personnel carrying out firefighting. An engineered suppression system is expected to control, if not actually suppress, the fire to eliminate the risk of smoke gas explosions or backdrafts.

In oil and gas processing plants, the training must rightfully be aimed at the most likely fire and explosion scenarios (i.e., ignited hydrocarbon leaks). This may, however, also be the main explanation for the potential of an ignitable smoke layer not being recognized by the operators and the ERT managers. If civil sector firefighters were exposed to a similar situation, it is quite likely that they would have recognized that a room partly filled with pyrolysis products, as indicated in Figure 5, could result in a possible smoke gas explosion or backdraft. They could then have acted according to their previous training for such incidents. It is therefore recommended that electrical incidents and general fire theory regarding classical fire development in enclosures [7,9] including special cases such as backdraft and smoke gas explosions $[8,9,25,26]$ are also given proper attention. This goes for the oil and gas industry as well as other process industries and power production and power transmission facilities. 
In the aftermath of the incident, it was therefore decided to start developing a training program for plant operators that highlighted electrical fire and explosion risk and compartment fire dynamics. The compartment fire dynamics session should include fire and compartment interactions (i.e., classical fire development through flashover [7,9], backdraft and smoke gas explosions $[8,9,25,26])$.

In the literature, there are many published studies regarding personal injuries and explosions triggered by short-circuiting high-voltage systems (e.g., [27-29]). The incident analyzed in the present work represents a situation that is quite unfamiliar in the oil and gas industry, and literature describing similar quasi-smoke gas explosion incidents was not found. According to Babrauskas [10], this may be due to the fact that high-voltage room fires only account for a minor fraction of electrical fires and thus make a small contribution to fire deaths, while series arcs represent a high-frequency cause of fires [29]. It is, however, quite likely that similar quasi-smoke gas incidents have happened in other facilities handling high-voltage systems. Very often, such incidents are, however, treated locally, and the lessons learned are unfortunately not shared beyond the affected companies. The motivation for the present study is to share important learning points in order to prevent similar incidents and potential severe injuries to personnel in other facilities.

The main learning points are related to proper monitoring and maintenance of electrical equipment, alarm management, and operator safety training. Adequately maintained relays and a risk-based replacement frequency could significantly reduce the risk of malfunctioning. Addressed alarm messages to the central control room regarding smoke production, temperature increase or visible flames would significantly reduce the delay in initial fire investigations, thereby reducing the possible consequences to personnel and assets. Giving plant operators training in possible electrical incidents, in combination with basic compartment fire dynamics, would be very beneficial for handling surprising situations with regard to both personnel safety and asset protection. All the above measures could also reduce the risk of downtime and lost production associated with fires caused by electrical malfunctions.

Author Contributions: Field investigation, M.S.B. and E.K.H.; Field interviews, M.S.B. and E.K.H.; Scientific literature review, T.L.; Data curation, E.K.H. and T.L.; Fire and explosion risk analysis, T.L.; Resources, M.S.B.; Writing-original draft preparation, T.L.; Writing—review and editing, M.S.B., E.K.H., and T.L. All authors have read and agreed to the published version of the manuscript.

Funding: This research received no external funding.

Acknowledgments: The decision by Lena Skogly, Operations at the Equinor Tjeldbergodden process plant, to pursue the present study is greatly appreciated, as are the improvements suggested by the anonymous reviewers.

Conflicts of Interest: The authors declare no conflicts of interest.

\section{References}

1. Cullen, D. The Public Inquiry into the Piper Alpha Disaster; H.M. Stationery Office: London, UK, $1990 ;$ p. 488. ISBN 0101113102.

2. Drysdale, D.D.; Sylvester-Evans, R. The explosion and fire on the Piper Alpha platform, 6 July 1988. A case study. Phil. Trans. Royal Soc. A Math. Phys. Eng. Sci. 1998, 356, 2929-2951. [CrossRef]

3. Broadribb, M.P. What have we really learned? Twenty five years after Piper Alpha. Proc. Saf. Prog. 2014, 34, 16-23. [CrossRef]

4. Investigation Report: Refinery Explosion and Fire (15 killed, 180 Injured); Report No. 2005-04-I-TX; BP Texas City Refinery: Texas City, TX, USA, 2005; U.S. Chemical Safety and Hazard Investigation Board: Washington, DC, USA, 2007.

5. Hendershot, D.C. Texas City-Ten years later. J. Chem. Health and Safety 2015, 22, 38-39. [CrossRef]

6. Kaszniak, M.; Holmstrom, D. Trailer siting issues: BP Texas City. J. Haz. Mat. 2008, 159, 105-111. [CrossRef]

7. Drysdale, D. An Introduction to Fire Dynamics, 2nd ed.; John Wiley: New York, NY, USA, 1999; p. 476. ISBN 0-471-97291-6.

8. Fleischmann, C.M.; Chen, Z.J. Defining the difference between backdraft and smoke explosions. Procedia Eng. 2013, 62, 324-330. [CrossRef] 
9. Karlsson, B.; Quintiere, J.G. Enclosure Fire Dynamics; CRC Press LLC: London, UK, 1999; p. 315. ISBN 0-8493-1300-7.

10. Babrauskas, V. Research on electrical fires: The state of the art. Fire Safety Sci. 2009, 9, 3-18. [CrossRef]

11. Majstrovic, M.; Sutlovic, E.; Ramljak, I. Critical diameter of particles produced in overhead line conductor clashing. Appl. Therm. Eng. 2017, 114, 713-718. [CrossRef]

12. Ramljak, I.; Majstrovic, M.; Sutlovic, E. Statistical analysis of particles of conductor clashing. In Proceedings of the ENERGYCON, Dubrovnik, Croatia, 13-16 May 2014; p. 6.

13. Fernandez-Pello, A.C. Wildland fire spot ignition by sparks and firebrands. Fire Saf. J. 2017, 91, 2-10. [CrossRef]

14. Avidor, E.; Joglar-Billoch, F.J.; Mowrer, F.W.; Modarres, M. Hazard assessment of fire in electrical cabinets. Nucl. Technol. 2003, 144, 337-357. [CrossRef]

15. Wang, G.; Kim, W.-H.; Kil, G.-S.; Park, D.-W.; Kim, S.-W. An intelligent lightning warning system based on electromagnetic field and neural network. Energies 2019, 12, 1275. [CrossRef]

16. Bakka, M.S.; Handal, E.K.; Wilhelmsen, K.O.L.; Glomnes, E.; Søndenå, A. Brann Med Påfølgende Røykgasseksplosjon i Høyspentrom i Luftgassfabrikken På Tjeldbergodden [Fire and Succeeding Smoke Gas Explosion in the High-Voltage Room in the Air Gas Factory at Tjeldbergodden]; A 2018-25-MMP L1; Equinor (Internal) Corporate Investigation: Sandsli, Norway, 2020; p. 94.

17. Miandad, R.; Rehan, M.; Barakat, M.A.; Asad, S.; Aburiazaiza, A.S.; Khan, H.; Ismail, I.M.I.; Dhavamani, J.; Gardy, J.; Hassanpour, A.; et al. Catalytic pyrolysis of plastic waste: Moving toward pyrolysis based biorefineries. Front. Energy Res. 2019, 7, 1-17. [CrossRef]

18. Log, T. Skin temperatures of a pre-cooled wet person exposed to engulfing flames. Fire Saf. J. 2017, 89, 1-6. [CrossRef]

19. Log, T. Modeling burns for pre-cooled skin flame exposure. Int. J. Environ. Res. Public Health 2017, $14,1024$. [CrossRef] [PubMed]

20. Moi, A.L.; Haugsmyr, E.; Heisterkamp, H. Long-term study of health and quality of life after burn injury. Ann. Burn. Fire Disasters 2016, 29, 295-299.

21. Log, T.; Moi, A.L. Ethanol and methanol burn risks in the home environment. Int. J. Environ. Res. Public Health 2018, 15, 2379. [CrossRef]

22. Zhang, G.W.; Zhu, G.Q.; Yuan, G.L.; Huang, L.L. Methods for prediction of temperature distribution in flashover caused by backdraft fire. Math. Prob. Eng. 2014, 2014, 707423. [CrossRef]

23. Poulsen, A.; Bwalya, A.; Jomaas, G. Evaluation of the onset of flashover in room fire experiments. Fire Technol. 2013, 49, 891-905. [CrossRef]

24. Bengtsson, L.G. Enclosure Fires; NRS Tryckeri: Huskvarna, Sweden, 2001; p. 194. ISBN 91-7253-263-7.

25. Croft, W.M. Fires Involving Explosions-A Literature Review. Fire Saf. J. 1980, 3, 3-24. [CrossRef]

26. Lu, J.Z.; Chen, B.H.; Liang, P.; Sun, Y.; Fang, Z.; Huang, S. Experimental evaluation of protecting high-voltage electrical transformers using water mist with and without additives. Fire Technol. 2019, 55, 1671-1690. [CrossRef]

27. Gass, B. Substation accident: A case study. In Proceedings of the 64th Assoc. of Municipal Electricity Utilities (AMEU) Convention, Mirand, South Africa, 5-8 October 2014; pp. 84-86.

28. Adekunle, A.; Asaolu, G.O.; Adiji, K.; Bamiduro, H.A. Impacts of electrical hazards on Nigerian construction industries with a view to provide safety measures-Case study of Kaptron Technologies. J. Sustain. Dev. Stud. 2016, 9, 267-289.

29. Ji, H.-K.; Wang, G.; Kim, W.-H.; Kil, G.-S. Optimal design of a band pass filter and an algorithm for series arc detection. Energies 2018, 11, 992. [CrossRef]

(C) 2020 by the authors. Licensee MDPI, Basel, Switzerland. This article is an open access article distributed under the terms and conditions of the Creative Commons Attribution (CC BY) license (http://creativecommons.org/licenses/by/4.0/). 